Check for updates

Cite this: RSC Adv., 2017, 7, 47583

Received 1st September 2017

Accepted 27th September 2017

DOI: 10.1039/c7ra09715h

rsc.li/rsc-advances

\title{
Molecular dynamics simulation for the impact of an electrostatic field and impurity $\mathrm{Mg}^{2+}$ ions on hard water
}

\begin{abstract}
Lin Zhu, (D) a Yong Han, (D) *a Chuanxin Zhang, ${ }^{a}$ Ruikuan Zhao and Shoufeng Tang ${ }^{\mathrm{b}}$
A detailed analysis of the structural parameters and dynamic parameters of hard water solutions under an external electrostatic field was performed by molecular dynamics (MD) simulations with the presence of impurity $\mathrm{Mg}^{2+}$ ions. The $\mathrm{CaCl}_{2}$ aqueous solution was chosen in the study as hard water because calcium carbonate is the main component of water scale. The effects on the $\mathrm{CaCl}_{2}$ aqueous solution caused by adding different numbers of $\mathrm{Mg}^{2+}$ ions and using an electrostatic field are examined in terms of the selfdiffusion coefficient of $\mathrm{Ca}^{2+}$ ions and water molecules, the residence time of water molecules in the first water shell of $\mathrm{Ca}^{2+}$ ions, solution viscosity, characteristics of hydrogen bonds and some structural parameters, and how these effects influence the formation process of calcium carbonate when there are $\mathrm{CO}_{3}{ }^{2-}$ ions. The goal behind the study is to attain additional insights into the influence on the scaleinhibiting performance with the presence of impurity $\mathrm{Mg}^{2+}$ ions when electrostatic anti-fouling technology is used practically in hard water.
\end{abstract}

\section{Introduction}

The scale issue is a key problem in heat exchangers, such as cooling towers and boilers. Scaling causes at least two problems: degradation in the performance of heat exchangers and a decrease of flow rate or an increase in pressure drop across the heat exchanger. To solve the scale problem, electrostatic antifouling (EAF) systems are used. Many researchers have studied the anti-fouling mechanism of the EAF system. Calcium carbonate is the main component of water scale. Therefore, the vast majority of researchers who investigate the anti-fouling mechanism of EAF systems focus on the effect of electromagnetic fields on calcium carbonate. It mainly includes two aspects: the formation process of calcium carbonate crystallization and the change in the crystal structure of scale under an electromagnetic field. Qi et al. ${ }^{1}$ investigated the effect of an electric field (EF) on the crystallization of calcium carbonate. Their results showed that the lattice structure and crystalline morphology of $\mathrm{CaCO}_{3}$ can be tailored by the electric field applied to the solution during its crystallization. Liu et al. ${ }^{2}$ found that the content of aragonite increased in the scale sample formed in electrostatic water.

However, although the composition of scale is mainly calcium carbonate, there is a small amount of precipitation

${ }^{a}$ Measurement Technology and Instrumentation Key Laboratory of Hebei Province, School of Electrical Engineering, Yanshan University, Qinhuangdao 066004, P. R. China.E-mail: hanyong@ysu.edu.cn

${ }^{b}$ School of Environmental and Chemical Engineering, Yanshan University, Qinhuangdao 066004, P. R. China formed by $\mathrm{Mg}^{2+}$ ions, such as magnesium carbonate and magnesium hydroxide, which are produced by $\mathrm{Mg}^{2+}$ and exist in natural water at high temperatures. Therefore some researchers have studied the effect of $\mathrm{Mg}^{2+}$ ions on the crystal structure of calcium carbonate. Mitsutaka Kitamura ${ }^{3}$ studied the crystallization and transformation mechanisms of calcium carbonate polymorphs under the effect of $\mathrm{Mg}^{2+}$. The experimental results showed that $\mathrm{Mg}^{2+}$ ions can inhibit the growth of calcite and suppress vaterite transformation to calcite. Gutjahr et $a .^{4}$ studied the influence of the divalent cation $\mathrm{Mg}^{2+}$ on the growth and dissolution rates of calcite and aragonite. The results showed that ions of the transition metals exhibit stronger inhibition than earth alkaline ions, and $\mathrm{Mg}^{2+}$ has no influence on the growth and dissolution of aragonite. DeLeeuw ${ }^{5}$ found that the presence of magnesium and iron ions inhibits calcite growth using molecular dynamics simulations. However, the influence on the microcosmic particle structure in aqueous solutions containing impurity ions under an electrostatic field has received less attention.

There are almost no $\mathrm{CO}_{3}{ }^{2-}$ ions in hard water because of the very low solubility of calcium carbonate. But many $\mathrm{HCO}_{3}{ }^{-}$ions exist. $\mathrm{Ca}^{2+}$ ions exist in aqueous solution as hydrated ions. These hydrated ions are also combined with other water molecules by hydrogen bonding. ${ }^{6-8}$ The structural and dynamical properties of $\mathrm{Ca}^{2+}$ directly affect the formation, growth and crystal structure of calcium carbonate precipitation. Therefore, research to determine the influence of an electrostatic field and $\mathrm{Mg}^{2+}$ ions on the structure and dynamics of hydrated $\mathrm{Ca}^{2+}$ may help discern the anti-fouling mechanism of EAF technology. ${ }^{9-17}$ In the present study, a mixed solution of calcium chloride and 
magnesium chloride was chosen. The structure and dynamics performance of the $\mathrm{CaCl}_{2}$ aqueous solution (the viscosity of the $\mathrm{CaCl}_{2}$ aqueous solution, the location of the first water shell of $\mathrm{Ca}^{2+}$, the structure of the hydrated $\mathrm{Ca}^{2+}$ and the self-diffusion coefficient of $\mathrm{Ca}^{2+}$ and water molecules, and the hydrogen bonding in solution) under an external electrostatic field with different numbers of $\mathrm{Mg}^{2+}$ ions added were studied using MD simulations.

\section{Model and simulation details}

The MD simulation used in the present study was an equilibrium MD simulation process. All MD simulations in this work were performed using the Gromacs 5.0.2 software. ${ }^{18}$ The length of the simulation box is $4 \mathrm{~nm} \times 4 \mathrm{~nm} \times 3 \mathrm{~nm}$. To study the effect of $\mathrm{Mg}^{2+}$ on the $\mathrm{CaCl}_{2}$ aqueous solution system under the electrostatic field, four sets of aqueous solution systems were built as shown in Table 1 . The concentration of the $\mathrm{CaCl}_{2}$ aqueous solution was $4 \mathrm{~mol} \mathrm{~kg}^{-1}$, and the concentration uncertainties between simulations and experiments were below $0.5 \% .^{12}$ The SPCE model was adopted for water molecules in our work. The GROMOS force field ${ }^{\mathbf{1 9 - 2 1}}$ was used in this simulation for ion-water interactions. For Lennard-Jones interactions, a cut-off was applied at $0.7 \mathrm{~nm}$, while electrostatic interactions were treated with the particle mesh Ewald (PME) ${ }^{\mathbf{2 0}}$ method and a real space cut-off of $0.7 \mathrm{~nm}$. The value of Fourier spacing is $0.12 \mathrm{~nm}$. Table 2 presents the Lennard-Jones potential parameters for particles used in the GROMOS force field. The time step used for all the simulations was 2.0 fs. The simulation time was $2.5 \times 10^{4} \mathrm{ps}$. Averages of parameters (except the data of the self-diffusion coefficient) were obtained from the last $1.5 \times 10^{4}$ ps of every simulation and the averages of parameters were obtained by calculating the average value of $1.5 \times 10^{4} \mathrm{ps}$, which was divided into ten segments. The type of integration algorithm for the equations of motion is the Leap frog algorithm. The temperature was set at $300 \mathrm{~K}$. The pressure was set at $1.01 \times$ $10^{5} \mathrm{~Pa}$. All simulations were carried out in NPT ensembles.

The study consists of two parts. In the first part, a different number of $\mathrm{Mg}^{2+}$ ions was added to the $\mathrm{CaCl}_{2}$ aqueous solution compared to the condition of no $\mathrm{Mg}^{2+}$ ions added. In the second part, an external electrostatic field was added compared to the condition of no electrostatic field. The electrostatic field had an intensity of $1 \mathrm{~V} \mathrm{\mu m}^{-1}$. The electrostatic field was applied along a given direction (corresponding to the $y$-axis). The correctness

Table 1 Composition of the calcium chloride solution studied by Gromacs $^{a}$

\begin{tabular}{llllll}
\hline Sample & {$\left[\mathrm{H}_{2} \mathrm{O}\right]$} & {$\left[\mathrm{Mg}^{2+}\right]$} & {$\left[\mathrm{Ca}^{2+}\right]$} & {$\left[\mathrm{Cl}^{-}\right]$} & {$[$Total $]$} \\
\hline $0 \mathrm{M}$ & 1110 & 0 & 80 & 160 & 1350 \\
$1 \mathrm{M}$ & 1110 & 10 & 80 & 180 & 1380 \\
$2 \mathrm{M}$ & 1110 & 20 & 80 & 200 & 1410 \\
$3 \mathrm{M}$ & 1110 & 30 & 80 & 220 & 1440
\end{tabular}

${ }^{a}$ Note: "0M" means no $\mathrm{Mg}^{2+}$ ions are added, " $1 \mathrm{M}$ " means $10 \mathrm{Mg}^{2+}$ ions are added, " $2 \mathrm{M}$ " means $20 \mathrm{Mg}^{2+}$ ions are added and " $3 \mathrm{M}$ " means 30 $\mathrm{Mg}^{2+}$ ions are added.
Table 2 Lennard-Jones potential parameters used in the MD simulations. According to Lorentz and Berthelot combining rules, i.e. $\varepsilon_{i j}=$ $\left(\varepsilon_{i i} \varepsilon_{i j}\right)^{1 / 2}$ and $\sigma_{i j}=\left(\sigma_{i i}+\sigma_{j j}\right) / 2$

\begin{tabular}{lll}
\hline & $\varepsilon /\left(\mathrm{kJ} \mathrm{mol}^{-1}\right)$ & $\sigma / \mathrm{nm}$ \\
\hline $\mathrm{Ca}^{2+}$ & 0.5069 & 0.2813 \\
$\mathrm{Mg}^{2+}$ & 0.3126 & 0.1933 \\
$\mathrm{Cl}^{-}$ & 1.2889 & 0.3470 \\
$\mathrm{O}$ & 1.7250 & 0.2626 \\
\hline
\end{tabular}

of our MD simulations and error analysis has been verified in previous work. ${ }^{22}$

\section{Results and discussion}

\subsection{Self-diffusion coefficients of $\mathrm{Ca}^{2+}$ ions and water molecules}

In this section the self-diffusion coefficients of $\mathrm{Ca}^{2+}$ and water molecules were studied when there is an external electrostatic field and a small number of $\mathrm{Mg}^{2+}$ ions in the $\mathrm{CaCl}_{2}$ aqueous solution system. The self-diffusion coefficient of ions is an important parameter which can influence the chemical reaction process in aqueous solution systems. In addition, the self-diffusion coefficient can vary significantly when the structure of the cation or anion changes or when some other kind of ion gets involved. ${ }^{23}$

In this paper, the self-diffusion coefficients of $\mathrm{Ca}^{2+}\left(D_{\mathrm{Ca}}\right)$ and water molecules $\left(D_{\mathrm{o}}\right)$ are calculated based on the "Einstein relation": ${ }^{24}$

$$
D=\lim _{t \rightarrow \infty} \frac{1}{6 t}\left\langle\left[r_{i}(t)-r_{i}(0)\right]^{2}\right\rangle
$$

where $r_{i}(t)$ is the molecule position $i$ at time $t$, hence $r_{i}(0)$ is the initial position and the bracket represents the ensemble average. A specific step in calculating the self-diffusion coefficient of particles is to fit the slope of the linear portion of the mean square displacement (MSD) and to divide by 6 . The linear portion of the MSD is determined by the RANSAC algorithm. RANSAC is an algorithm for the robust fitting of models in the presence of data outliers. ${ }^{25}$

Fig. 1 shows the effect of $\mathrm{Mg}^{2+}$ on the self-diffusion coefficients of $\mathrm{Ca}^{2+}$ and water molecules under an electrostatic field and with no electrostatic field. The standard deviations of the simulation data presented in Fig. 1 are conservatively estimated to be in the range of $0.0046 \% \times 10^{-5}-0.0078 \% \times 10^{-5} \mathrm{~cm}^{2} \mathrm{~s}^{-1}$ for self-diffusion coefficients. According to Fig. 1, the diffusion coefficients of $\mathrm{Ca}^{2+}$ and water molecules both decrease with the addition of $\mathrm{Mg}^{2+}$ whether there is an electrostatic field or not. Moreover, the more $\mathrm{Mg}^{2+}$ ions added, the lower the selfdiffusion coefficients of $\mathrm{Ca}^{2+}$ and water molecules are. Under no electrostatic field, when ten $\mathrm{Mg}^{2+}$ ions are added, $D_{\mathrm{o}}$ and $D_{\mathrm{Ca}}$ have maximum values of $0.5505 \times 10^{-5} \mathrm{~cm}^{2} \mathrm{~s}^{-1}$ and $0.0570 \times$ $10^{-5} \mathrm{~cm}^{2} \mathrm{~s}^{-1}$, respectively. When thirty $\mathrm{Mg}^{2+}$ ions are added, $D_{\mathrm{o}}$ and $D_{\mathrm{Ca}}$ have a minimum value of $0.3223 \times 10^{-5} \mathrm{~cm}^{2} \mathrm{~s}^{-1}$ and $0.0250 \times 10^{-5} \mathrm{~cm}^{2} \mathrm{~s}^{-1}$, respectively. In addition, Fig. 1(a) shows that the external electrostatic field can make the self-diffusion coefficient of water molecules larger no matter how many 

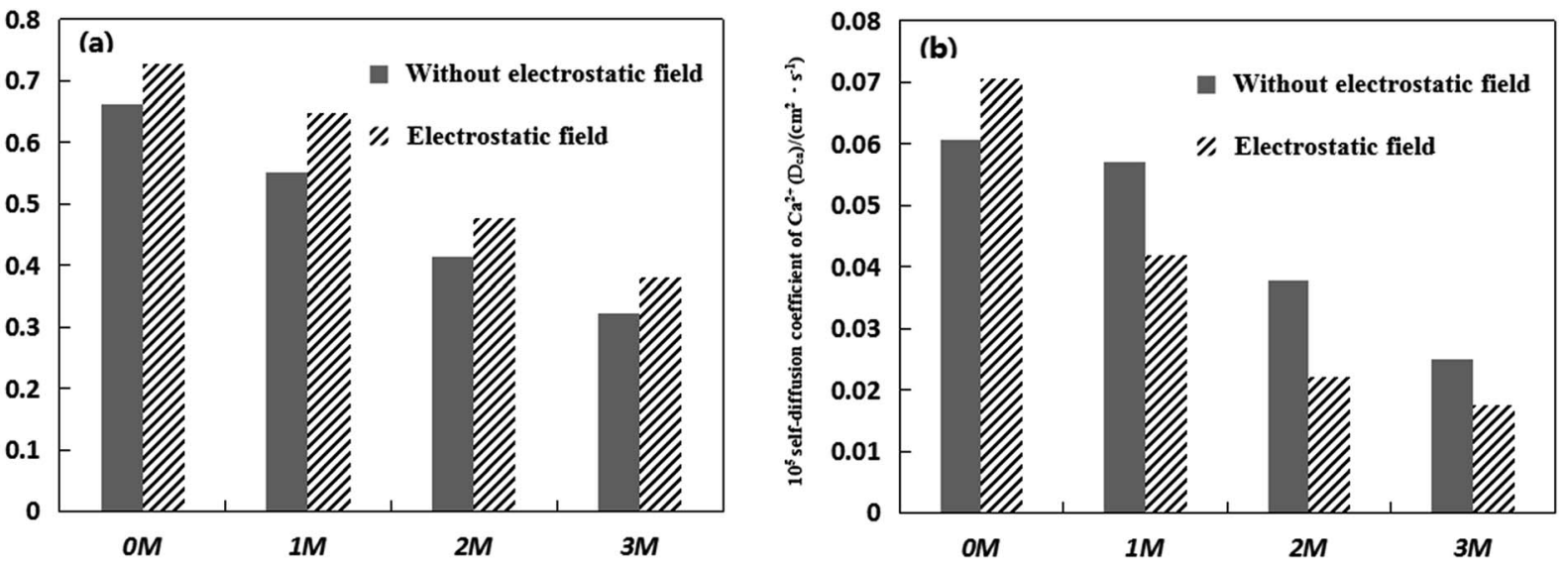

Fig. $110^{5}$ self-diffusion coefficient of water molecules $\left(D_{\circ}\right)$ and $\mathrm{Ca}^{2+}\left(D_{\mathrm{Ca}}\right)$ with no $\mathrm{Mg}^{2+}$ ions added $(0 \mathrm{M})$, ten $\mathrm{Mg}^{2+}$ ions added $(1 \mathrm{M})$, twenty $\mathrm{Mg}{ }^{2+}$ ions added (2M) and thirty $\mathrm{Mg}^{2+}$ ions added (3M) under no electrostatic field and under an electrostatic field.

$\mathrm{Mg}^{2+}$ ions are added to the $\mathrm{CaCl}_{2}$ aqueous solution in all simulations. According to Fig. 1(b), the external electrostatic field can make the self-diffusion coefficient of $\mathrm{Ca}^{2+}$ larger without $\mathrm{Mg}^{2+}$ addition, which is consistent with the results of our previous study. ${ }^{26}$ However, the electrostatic field can make the self-diffusion coefficient of $\mathrm{Ca}^{2+}$ smaller when $\mathrm{Mg}^{2+}$ ions are added to the $\mathrm{CaCl}_{2}$ aqueous solutions, which means that the combination of impurity $\mathrm{Mg}^{2+}$ and of an external electrostatic field can limit the activity of $\mathrm{Ca}^{2+}$ more strongly.

In the aqueous solution system, the valence state and structural order of cations can influence the diffusivity of water molecules. ${ }^{27}$ $\mathrm{Mg}^{2+}$ ions lose two electrons and, hence, have a strong binding ability towards water molecules. The first water shell of $\mathrm{Mg}^{2+}$, which consists of six water molecules, has octahedral symmetry. The stability of the nearest shell surrounding the $\mathrm{Mg}^{2+}$ ions justifies the assumption that the ion and its first shell can be considered as a solute..$^{28,29} \mathrm{To}$ sum up, when $\mathrm{Mg}^{2+}$ ions are added to the $\mathrm{CaCl}_{2}$ solution, the strong ability of $\mathrm{Mg}^{2+}$ to bind water molecules makes the activity of water molecules more limited..$^{30}$ The self-diffusion coefficient of water molecules decreases. And the more $\mathrm{Mg}^{2+}$ ions added, the more limited the activity of the water

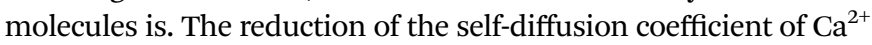
can be attributed to the presence of $\mathrm{Mg}^{2+}$. The electrostatic interaction between $\mathrm{Mg}^{2+}$ and water molecules makes the $\mathrm{CaCl}_{2}$ aqueous solution more compact, which limits the activity of $\mathrm{Ca}^{2+}$, and hence reduces the self-diffusion coefficient of $\mathrm{Ca}^{2+}$.

When the electrostatic field is applied to the pure water solution, the order of the water molecules and the strength of the hydrogen bonds are enhanced, which decrease the selfdiffusion coefficient of the water molecules. ${ }^{31}$ It means that the electrostatic field strengthens the correlation ability of the

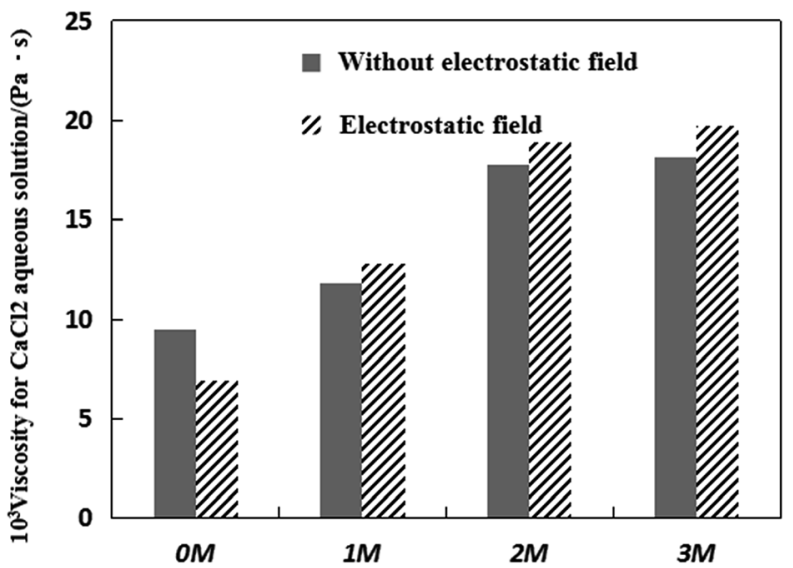

Fig. $210^{3}$ average viscosity with no $\mathrm{Mg}^{2+}$ ions added (OM), ten $\mathrm{Mg}^{2+}$ ions added (1M), twenty $\mathrm{Mg}^{2+}$ ions added (2M) and thirty $\mathrm{Mg}^{2+}$ ions added (3M) under no electrostatic field and under an electrostatic field.

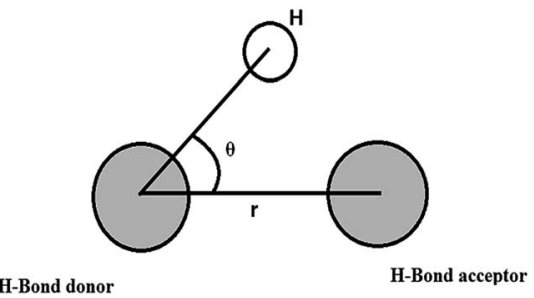

Fig. 3 Geometrical hydrogen bond criterion.

water molecules and the hydrogen bond network in a pure water solution. However, the results in Fig. 1(a) show that the electrostatic field can make the self-diffusion coefficient of water

Table 3 The mean dynamical residence time of water around $\mathrm{Ca}^{2+}(\mathrm{ps})$ in the four $\mathrm{CaCl}_{2}$ solutions

\begin{tabular}{|c|c|c|c|c|c|c|c|c|}
\hline & \multicolumn{4}{|c|}{ Without an electrostatic field } & \multicolumn{4}{|c|}{ Under an electrostatic field } \\
\hline & $0 \mathrm{M}$ & $1 \mathrm{M}$ & $2 \mathrm{M}$ & $3 \mathrm{M}$ & $0 \mathrm{M}$ & $1 \mathrm{M}$ & $2 \mathrm{M}$ & $3 \mathrm{M}$ \\
\hline
\end{tabular}




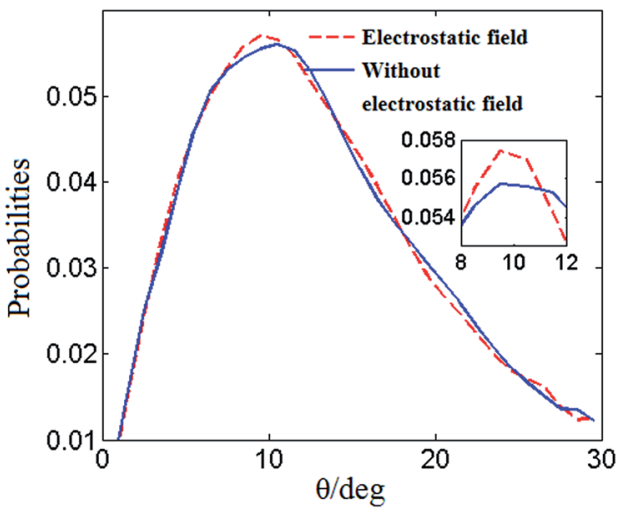

Fig. 4 Distribution of the hydrogen bond angle $\theta$ without an electrostatic field (solid line) and with an electrostatic field (dashed line).

molecules larger for the four representative $\mathrm{CaCl}_{2}$ aqueous solutions. Therefore, the increase of the diffusion coefficient of water molecules in the $\mathrm{CaCl}_{2}$ aqueous solution should be due to the activity of existing metal ions. The increase of the self-diffusion coefficient of water molecules illustrates that the electrostatic field increases the ionic motion and influences the relatively stable water molecules' hydrogen bond network.

The electrostatic field can not only reduce the diffusion coefficient of $\mathrm{Ca}^{2+}$ but also increase the diffusion coefficient of water molecules in the $\mathrm{CaCl}_{2}$ aqueous solution when the $\mathrm{Mg}^{2+}$ ions are added. The less active the $\mathrm{Ca}^{2+}$ ions, the smaller the chance of the chemical reaction produced by the combination of $\mathrm{Ca}^{2+}$ and $\mathrm{CO}_{3}{ }^{2-}$ is. As the self-diffusion coefficients of $\mathrm{Ca}^{2+}$ ions decrease, less $\mathrm{CaCO}_{3}$ precipitate is generated in solution. Therefore, the application of an electrostatic field with the addition of $\mathrm{Mg}^{2+}$ ions is beneficial to scale inhibition, which is consistent with some researchers' work, who have pointed out the inhibition effect of $\mathrm{Mg}^{2+}$ on calcium carbonate under an electrostatic field. ${ }^{5}$ Then the scale problem is alleviated.

\subsection{Dynamical residence time}

The residence time is another important parameter related to the dynamic structure of the solution. ${ }^{32}$ The residence time describes the stability of the water molecules, and is related to the strength of hydration..$^{33}$ Dynamical residence time $\gamma_{\text {res }}$ is defined as how long an atom or ion stays in a certain shell of another atom or ion. ${ }^{12}$ In the present paper the dynamical residence time of water molecules in the first hydration shell of $\mathrm{Ca}^{2+}$ was studied to investigate the translational dynamics of the water molecule. The dynamical residence time was calculated using eqn (2): ${ }^{34}$

$$
\gamma=\frac{1}{N_{\mathrm{h}}} \sum_{i=1}^{N_{\mathrm{h}}} \gamma_{i}
$$

where $N_{\mathrm{h}}$ is the hydration number of the shell, and $\gamma_{i}$ is the residence time of the water molecule $i$, which is calculated with eqn (3):

$$
\gamma_{i}=\frac{t_{i}}{n_{i}}
$$

where $t_{i}$ is the total time length (picoseconds, ps) of water molecules $i$ staying at the layer assigned, and $n_{i}$ is the number of times water molecules $i$ leave and come back to the layer assigned.

Table 3 shows the mean dynamical residence time of water around $\mathrm{Ca}^{2+}$ in four representative $\mathrm{CaCl}_{2}$ aqueous solutions under the electrostatic field. The values of $\gamma_{\text {res }}$ under no electrostatic field have been presented for comparison. The standard deviation of $\gamma_{\text {res }}$ is between 0.0086 ps and 0.0095 ps. According to Table 3, under the electrostatic field the mean dynamical residence time of water molecules around $\mathrm{Ca}^{2+}$ decreased. In addition, it can be found that the mean dynamical residence time of water around $\mathrm{Ca}^{2+}$ rises with the increase in the number of $\mathrm{Mg}^{2+}$ ions added in $\mathrm{CaCl}_{2}$ systems whether the electrostatic field is applied or not.

Naor $e t$ al. $^{35}$ studied $\mathrm{Ca}^{2+}$ in liquid water using the Car-Parrinello molecular dynamics simulation finding that the $\gamma_{\mathrm{res}}$ is 10 ps. Schwenk et al. ${ }^{36}$ studied the dynamics of the solvation process of $\mathrm{Ca}^{2+}$ in water based on DFT/MM and QM/MM-HF simulations and the results showed that $\gamma_{\text {res }}$ is 1.2 ps and 2 ps, respectively. According to Table 3, the values of $\gamma_{\text {res }}$ are distributed in the range of 3 to $5 \mathrm{ps}$, which are similar to the results given in the literature. The increase in the mean
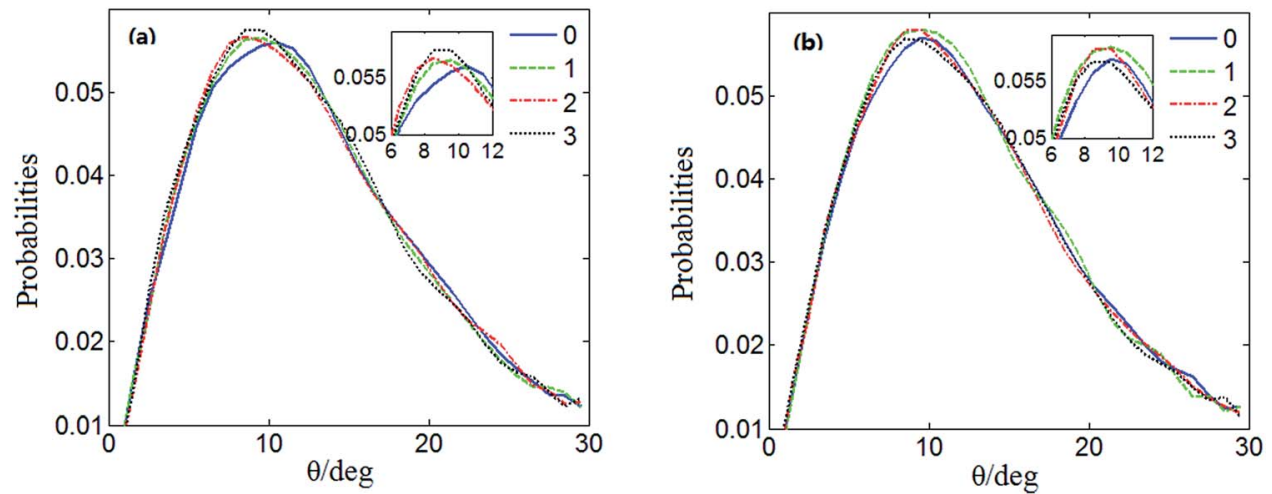

Fig. 5 Distribution of the hydrogen bond angle $\theta$ with no $\mathrm{Mg}^{2+}$ ions added (solid line), ten $\mathrm{Mg}^{2+}$ ions added (dashed line), twenty $\mathrm{Mg}^{2+}$ ions added (dash-dotted line) and thirty $\mathrm{Mg}^{2+}$ ions added (dotted line). (a) is under no electrostatic field and (b) is under an electrostatic field. 
Table 4 The percentage of water molecules with $n$ hydrogen bonds $\left(f_{n}\right)$, the number of $\mathrm{Mg}^{2+}$ ions added is $M(n \times 10 \mathrm{M})$, the average number of hydrogen bonds in water molecules $\left(n_{\mathrm{HB}}\right)$ and the average lifetime of hydrogen bonds $(\tau)$

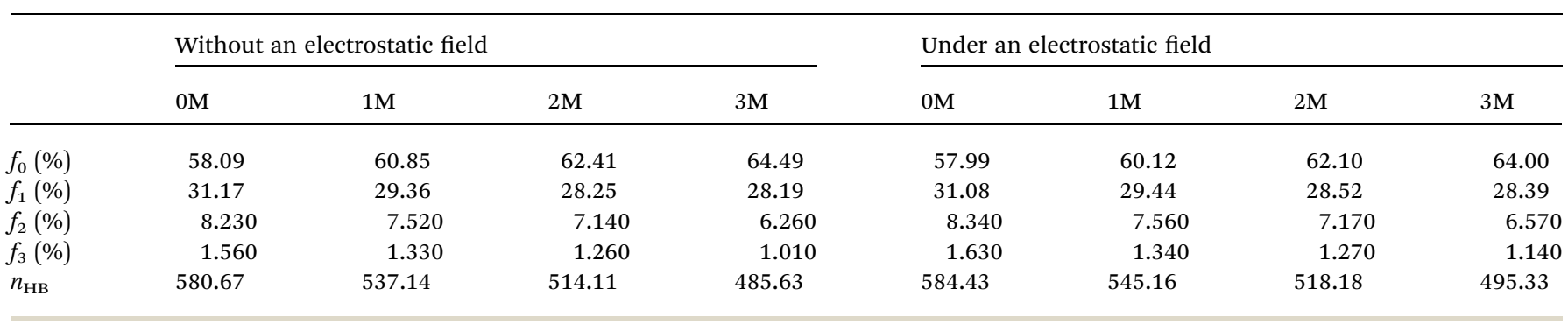

Table 5 Average lifetime of hydrogen bonds $(\tau)$ with a different number of $\mathrm{Mg}^{2+}$ ions (nM) added

\begin{tabular}{|c|c|c|c|c|c|c|c|c|}
\hline & \multicolumn{4}{|c|}{ Without an electrostatic field } & \multicolumn{4}{|c|}{ Under an electrostatic field } \\
\hline & $0 \mathrm{M}$ & $1 \mathrm{M}$ & $2 \mathrm{M}$ & $3 \mathrm{M}$ & $0 \mathrm{M}$ & $1 \mathrm{M}$ & $2 \mathrm{M}$ & $3 \mathrm{M}$ \\
\hline$\tau(\mathrm{ps})$ & 52.06 & 53.18 & 54.27 & 55.99 & 52.21 & 53.23 & 54.54 & 56.37 \\
\hline
\end{tabular}

Table 6 Average radii of the first water shell of $\mathrm{Ca}^{2+}$ and first water coordination number of $\mathrm{Ca}^{2+}$ under the electrostatic field with different numbers of $\mathrm{Mg}^{2+}$ ions added

\begin{tabular}{|c|c|c|c|c|c|c|c|c|}
\hline & \multicolumn{4}{|c|}{$\begin{array}{l}\text { Without an electrostatic } \\
\text { field }\end{array}$} & \multicolumn{4}{|c|}{ Under an electrostatic field } \\
\hline & $0 \mathrm{M}$ & $1 \mathrm{M}$ & $2 \mathrm{M}$ & $3 \mathrm{M}$ & $0 \mathrm{M}$ & $1 \mathrm{M}$ & $2 \mathrm{M}$ & $3 \mathrm{M}$ \\
\hline$R_{\mathrm{Ca}-\mathrm{O}}(\mathrm{nm})$ & 0.282 & 0.282 & 0.280 & 0.282 & 0.278 & 0.280 & 0.276 & 0.280 \\
\hline$n_{\mathrm{Ca}-\mathrm{O}}$ & 5.62 & 5.30 & 5.07 & 5.00 & 5.70 & 5.41 & 5.22 & 4.90 \\
\hline
\end{tabular}

dynamical residence time of water molecules around $\mathrm{Ca}^{2+}$ is because of the change in the diffusion coefficient of water molecules. When $\mathrm{Mg}^{2+}$ ions are added to the calcium chloride solution, the electrostatic interaction between $\mathrm{Mg}^{2+}$ and water molecules makes the diffusion coefficient of water molecules decrease, which causes the water molecules around $\mathrm{Ca}^{2+}$ to move in and out of the first shell less frequently ${ }^{37}$ According to Table 3 , the electrostatic field can make the mean dynamical residence time of water molecules around $\mathrm{Ca}^{2+}$ in the four representative $\mathrm{CaCl}_{2}$ aqueous solutions decrease. This is because the activity of water molecules is enhanced by the electrostatic field, which makes the water molecules around $\mathrm{Ca}^{2+}$ move in and out of the first shell much more frequently. Therefore the mean dynamical residence time of water around $\mathrm{Ca}^{2+}$ decreased.

\subsection{Viscosity of the $\mathrm{CaCl}_{2}$ aqueous solution}

The dynamic viscosity of a liquid is a kinetic property that influences the rates of conformational changes of solutes in the liquid. It can be influenced by an electrostatic field. ${ }^{38}$ The viscosity $(\eta)$ can be calculated using the following equation:

$$
\eta=\frac{A}{V} \frac{\rho}{k^{2}}
$$

where $\rho$ and $V$ are the density and velocity, respectively; $A$ is a constant ${ }^{38}$ and from a cosine that satisfies both conditions:
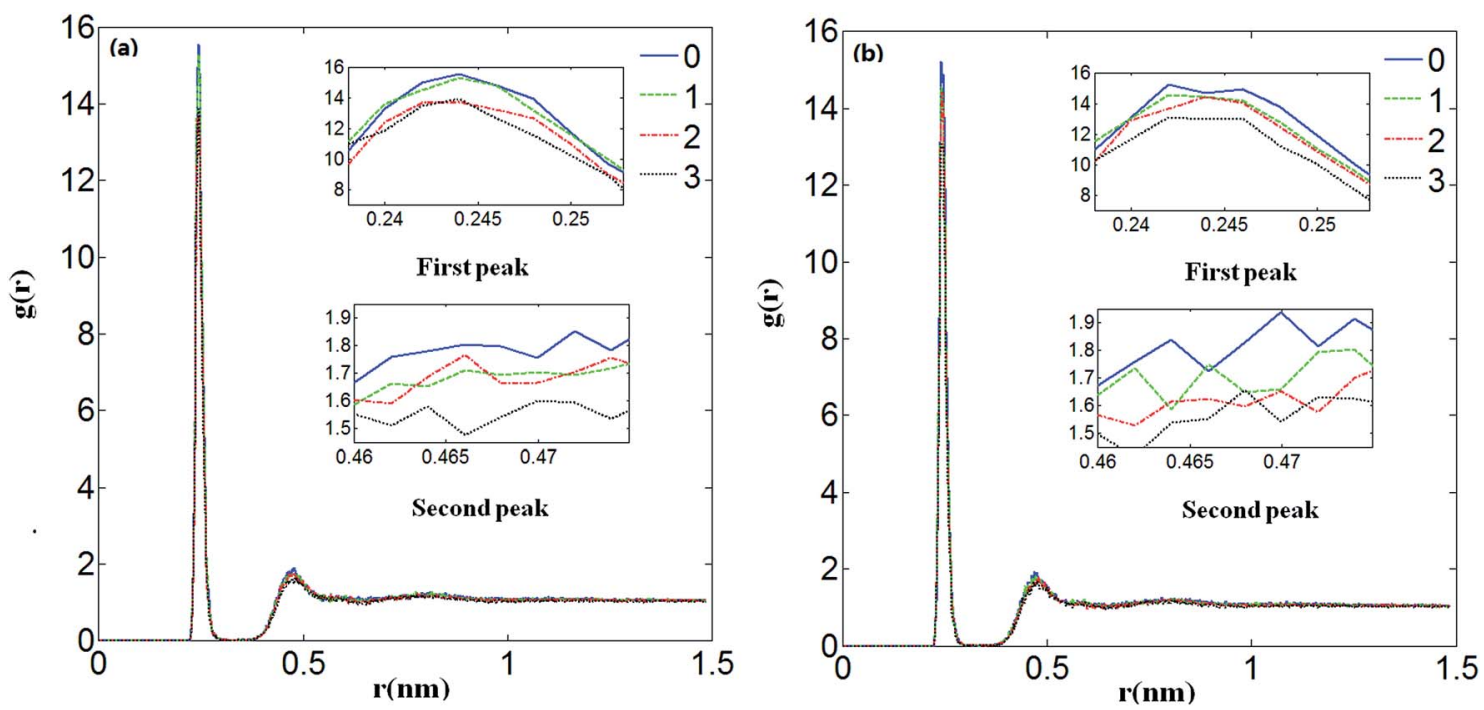

Fig. 6 Effects of $\mathrm{Mg}^{2+}$ ions on $\mathrm{g}(r)$ ion-water in the $\mathrm{CaCl}_{2}$ aqueous solution system with no $\mathrm{Mg}^{2+}$ ions added (solid line), ten $\mathrm{Mg}^{2+}$ ions added (dashed line), twenty $\mathrm{Mg}^{2+}$ ions added (dash-dotted line) and thirty $\mathrm{Mg}^{2+}$ ions added (dotted line) under no electrostatic field (a) and under the electrostatic field (b). 


$$
a_{x}=A \cos (k z), k=2 \pi / l_{z}
$$

where $l_{z}$ is the height of the box. We define the instantaneous $V$ in the simulation as a Fourier coefficient:

$$
V(t)=\frac{2 \sum_{i=1}^{N} m_{i} v_{i, x}(t) \cos \left[k r_{i, z}(t)\right]}{\sum_{i=1}^{N} m_{i}}
$$

where $v_{i, x}$ is the $x$ component of the velocity; $r_{i, z}$ is the $z$ coordinate; $m_{i}$ is the mass of an atom. The average of $V$ can be measured after the amplitude of the velocity profile has been fully developed.

Fig. 2 shows the viscosity of four representative $\mathrm{CaCl}_{2}$ aqueous solutions under an electrostatic field. The values under no electrostatic field are presented for comparison. From Fig. 2, it can be found that the viscosity of the four representative $\mathrm{CaCl}_{2}$ aqueous solutions increases under the action of $\mathrm{Mg}^{2+}$, and there is a positive correlation between the viscosity value and the number of $\mathrm{Mg}^{2+}$ ions added in the $\mathrm{CaCl}_{2}$ systems. In addition, the electrostatic field can make the viscosity of $\mathrm{CaCl}_{2}$ aqueous solutions smaller without the addition of $\mathrm{Mg}^{2+}$ ions. But the electrostatic field can make the viscosity of $\mathrm{CaCl}_{2}$ aqueous solutions increase when a certain amount of $\mathrm{Mg}^{2+}$ ions is added to the $\mathrm{CaCl}_{2}$ aqueous solutions.

The dynamic viscosity can be described as a type of friction caused by the fluid's motion inside the solution system. Its value is proportional to the number of carbon-hydrogen bonds and the particles' molecular weight in the solution system. It should be realized that the viscosity is a macroscopic property that represents the average behaviour of a large number of water molecules in aqueous solution. ${ }^{32}$ Therefore, the change in dynamic viscosity can be attributed to the changes in the structural and dynamics parameters of water molecules. Bakker $^{32}$ found that the large influence of some ions on the viscosity of water is due to the long lifetime of their first hydration shells using molecular dynamics simulations. The longer residence times of the water molecules in ion hydration shells strongly increases the viscosity. Since $\mathrm{CaCl}_{2}$ is an inorganic salt in an aqueous solution, there is no carbon-hydrogen bond in it. Therefore, the decrease in the viscosity of the $\mathrm{CaCl}_{2}$ solution should only be attributed to the changes in the structural change and dynamics parameters of water molecules. Combined with Fig. 2, the addition of $\mathrm{Mg}^{2+}$ forms a water shell which can result in a long residence time of water molecules in the $\mathrm{Mg}^{2+}$ hydration shells. Moreover, the addition of $\mathrm{Mg}^{2+}$ makes the mean dynamical residence time of water around $\mathrm{Ca}^{2+}$ increase as discussed earlier, which can also increase the viscosity of the $\mathrm{CaCl}_{2}$ aqueous solutions. This result can also match with the data in Fig. 1. The activity of water molecules is related to the viscosity of the solution. According to Fig. 1, the activity of water molecules is more limited when more $\mathrm{Mg}^{2+}$ ions are added, and this can make the viscosity of the solution increase. The results in Fig. 2, show that the electrostatic field can make the viscosity of $\mathrm{CaCl}_{2}$ aqueous solutions decrease without the addition of $\mathrm{Mg}^{2+}$ ions. The electrostatic field increases the activity of water molecules and decreases the mean dynamical residence time of water around $\mathrm{Ca}^{2+}$, which causes a decrease in the dynamic viscosity. In the case of the $\mathrm{CaCl}_{2}$ solution containing $\mathrm{Mg}^{2+}$, although the electrostatic field increases the activity of water molecules that can result in the viscosity decrease, the $\mathrm{Mg}^{2+}$ has a stronger binding ability with water molecules than $\mathrm{Ca}^{2+}$ due to the smaller effective radius ${ }^{37}$ and the longer lifetime of water molecules around $\mathrm{Mg}^{2+} \cdot{ }^{32}$ This means that $\mathrm{Mg}^{2+}$ has a stronger ability to increase the viscosity of the solution than $\mathrm{Ca}^{2+}$. The electrostatic interaction between $\mathrm{Mg}^{2+}$ ions and water molecules can make the viscosity of the solution increase. This ability is stronger than the ability of the electrostatic field to decrease the viscosity of the solution, which causes an increase in the dynamic viscosity of the $\mathrm{CaCl}_{2}$ solution. To sum up, a certain amount of $\mathrm{Mg}^{2+}$ can increase the viscosity of the $\mathrm{CaCl}_{2}$ aqueous solution, and when the electrostatic field is applied to the $\mathrm{CaCl}_{2}$ solution containing $\mathrm{Mg}^{2+}$, the viscosity of the $\mathrm{CaCl}_{2}$ aqueous solution can also be increased.

\subsection{Effects of $\mathrm{Mg}^{2+}$ ions and electrostatic fields on hydrogen bonds}

3.4.1 Structure and number of hydrogen bonds. The characteristics of hydrogen bonds are directly related to the physical and chemical properties of the aqueous solution. ${ }^{39,40}$ In the Gromacs software, the hydrogen bond is defined as the distance from a donor to an acceptor, which is less than the van der Waals (VDW) distance of $3.5 \AA(r)$ and the angle of the hydrogen-donor-acceptor is smaller than $30^{\circ} .{ }^{41}$ Fig. 3 shows the geometrical hydrogen bond criterion. In the present study receptors and donors are oxygen atoms in water molecules. The hydrogen bond angle calculated in this study is $\angle \mathrm{H}_{\mathrm{D}}-\mathrm{O}_{\mathrm{D}}-\mathrm{O}_{\mathrm{A}}(\theta)$ which is a useful angle often used in the literature that provides valuable insight into the flexibility of donor hydrogen bonds. ${ }^{42}$ When a molecule forms hydrogen bonds with another molecule, the overall hydrogen bonding potential of the molecule becomes larger. However, the angle variation will change the distance between atoms and the Coulomb force and van der Waals (VDW) force will also change, which influences the stability of hydrogen bonds. A hydrogen bond can be broken by an increase of water rotation (increasing $\theta$ ). ${ }^{42}$

Fig. 4 shows the distribution of the hydrogen bond angle $\theta$ under the electrostatic field and the value under no electrostatic field is presented for comparison. Fig. 5 shows the distributions of the hydrogen bond angle $\theta$ under no electrostatic field and under the electrostatic field with different numbers of $\mathrm{Mg}^{2+}$ ions added, respectively. For clarification, the peaks are enlarged in the small figures. The distributions of the hydrogen bond angle $\theta$ shown in Fig. 4 and Fig. 5 are Poisson distributions, which are similar to those obtained from other simulations. ${ }^{42,43}$

It can be seen in Fig. 5(a) that under no electrostatic field the peak coordinates of the distribution of the hydrogen bond angle $\theta$ are $(11.5,0.0560083),(9.5,0.0569745),(8.5,0.0562455)$ and $(9.5,0.0588264)$ when $0 \mathrm{Mg}^{2+}$ ions, ten $\mathrm{Mg}^{2+}$ ions, twenty $\mathrm{Mg}^{2+}$ ions, and thirty $\mathrm{Mg}^{2+}$ ions are added, respectively. According to Fig. 5(b), when $0 \mathrm{Mg}^{2+}$ ions, ten $\mathrm{Mg}^{2+}$ ions, twenty $\mathrm{Mg}^{2+}$ ions, and thirty $\mathrm{Mg}^{2+}$ ions are added, respectively, under an 
electrostatic field, the peak coordinates of the distribution of the hydrogen bond angle $\theta$ are $(9.5,0.0585088),(8.5,0.0585088)$, $(8.5,0.0592885)$ and $(7.5,0.0558013)$. It is shown in Fig. 5(a) and (b) that the positions of the statistical curve peaks all shift to smaller angles. The heights of the peaks all rise with the increase in the number of added $\mathrm{Mg}^{2+}$ ions and the application of an electrostatic field. Both the electrostatic field and $\mathrm{Mg}^{2+}$ ions can change the distribution of the hydrogen bond angle and make the average hydrogen bond angle smaller. It means that the $\mathrm{Mg}^{2+}$ and the electrostatic field can enhance the hydrogen bonding between water molecules to a certain extent.

In the present study the number of hydrogen bonds $\left(n_{\mathrm{HB}}\right)$ and the percentage of water molecules with $n$ hydrogen bonds $\left(f_{n}\right)$ are also investigated. The $f_{n}$ and $n_{\mathrm{HB}}$ in $\mathrm{CaCl}_{2}$ aqueous solutions without $\mathrm{Mg}^{2+}$ ions added (0M), with ten $\mathrm{Mg}^{2+}$ ions added (1M), with twenty $\mathrm{Mg}^{2+}$ ions added (2M) and with thirty $\mathrm{Mg}^{2+}$ ions added (3M) are listed in Table 4 . In addition, the influence of the electrostatic field is also presented.

According to Table 4, the electrostatic field can decrease the fraction of molecules having no hydrogen bonds, while it can increase the fraction of molecules having one to three hydrogen bonds and the average number of hydrogen bonds per water molecule whether $\mathrm{Mg}^{2+}$ is added or not. The reduction of $f_{0}$ and the increase of $n_{\mathrm{HB}}, f_{1}, f_{2}$, and $f_{3}$ show that the activity of water molecules is restrained and more water molecules shift from a free state to a hydrogen-bonded state, which means that the hydrogen bonding of water molecules was enhanced by the electrostatic field. The results in Table 4 also show that the $\mathrm{Mg}^{2+}$ ions can increase $f_{0}$ and decrease $n_{\mathrm{HB}}, f_{1}, f_{2}$, and $f_{3}$ whether the electrostatic field is applied or not. Furthermore, $f_{0}$ increases with the increase in the number of $\mathrm{Mg}^{2+}$ ions added, and $n_{\mathrm{HB}}, f_{1}$, $f_{2}$, and $f_{3}$ decrease with the increase in the number of $\mathrm{Mg}^{2+}$ ions added to the $\mathrm{CaCl}_{2}$ systems.

The electrostatic field of ions can influence the hydrogen bond structure when water molecules are in the vicinity of cations that do not form any hydrogen bonds. The water molecules in the cation hydration shells are also held through ion-dipole interactions. ${ }^{44}$ When the cation is present, more non hydrogen-bonded water molecules stay in the ion hydration shell due to attractive ion-dipole interactions. The number of water molecules bound by hydrogen bonding decreases. Then a smaller number of hydrogen bonds are formed, the fraction of molecules having no hydrogen bonds increases, and the fraction of molecules having one to three hydrogen bonds and the average number of hydrogen bonds per water molecule decrease.

3.4.2 Hydrogen bond lifetime. Hydrogen bond strength can be evaluated by calculating the lifetime of hydrogen bonds. It is a positive correlation between the lifetime of hydrogen bonds and the hydrogen bond strength. ${ }^{41}$ Since the water molecules are in rapid vibration, the hydrogen-bonded water molecules break at a certain time and then form hydrogen bonds with other water molecules. ${ }^{45}$ The hydrogen bond lifetime is a parameter that measures the different hydrogen bond lifetimes in different states throughout the dynamic process.

The lifetime of hydrogen bonds $\left(\tau_{\mathrm{HB}}\right)$ can be calculated using eqn (7): ${ }^{21}$

$$
\tau_{\mathrm{HB}}=\int_{0}^{\infty} C(\tau) \mathrm{d} \tau
$$

where $C(\tau)$ is the hydrogen bond correlation function. The $C(\tau)$ is defined as:

$$
C(\tau)=\left\langle h_{i}(t) h_{i}(t+\tau)\right\rangle
$$

where $h_{i}(t)=\{0,1\}$ is the Heaviside unit step function, and it means that if two molecules formed hydrogen bonds at time 0 and $t$, the function value is 1 , and otherwise 0 .

According to Table 5, the electrostatic field increases the average lifetime of the hydrogen bond whether $\mathrm{Mg}^{2+}$ is added or not. The increase of $\tau$ due to the hydrogen bonding of water molecules is enhanced by the electrostatic field as discussed earlier. In addition, the results in Table 5 show that the $\mathrm{Mg}^{2+}$ ions can increase the average lifetime of the hydrogen bond. The hydrogen bond formed in the cationic water shell is relatively strong. ${ }^{46}$ Therefore, the addition of $\mathrm{Mg}^{2+}$ can cause more water shells to form with water molecules which increases the average lifetime of the hydrogen bond.

\subsection{Structure parameters}

In this section, the average radii of the first water shell of $\mathrm{Ca}^{2+}$ ions $\left(R_{\mathrm{Ca}-\mathrm{O}}\right)$, the first coordination numbers of $\mathrm{Ca}^{2+}\left(n_{\mathrm{Ca}-\mathrm{O}}\right)$ and the RDF (radial distribution function) of $\mathrm{Ca}^{2+}$ and water molecules are discussed under the addition of $\mathrm{Mg}^{2+}$ ions, the external electrostatic field and no electrostatic field, respectively. $R_{\mathrm{Ca}-\mathrm{O}}$ can be obtained from the radial distribution function $[g(r)]$. The form of $[g(r)]^{47}$ is shown in eqn (9):

$$
g_{\mathrm{AB}}(r)=\frac{\left\langle\rho_{\mathrm{B}}(r)\right\rangle}{\left\langle\rho_{\mathrm{B}}(r)\right\rangle_{\text {local }}}=\frac{1}{\left\langle\rho_{\mathrm{B}}(r)\right\rangle_{\text {local }}} \frac{1}{N_{\mathrm{A}}} \sum_{i \in \mathrm{A}}^{N_{\mathrm{A}}} \sum_{j \in \mathrm{B}}^{N_{\mathrm{B}}} \frac{\delta\left(r_{i j}-r\right)}{4 \pi r^{2}}
$$

where $N_{\mathrm{A}}$ is the quantity of particle $\mathrm{A}$, and $N_{\mathrm{B}}$ is the quantity of particle $\mathrm{B} ;\left\langle\rho_{\mathrm{B}}(r)\right\rangle$ is the particle density of particle $\mathrm{B}$ at a distance $r$ from particle $\mathrm{A}$, and $\left\langle\rho_{\mathrm{B}}(r)\right\rangle_{\text {local }}$ is the particle density of particle $\mathrm{B}$ averaged over all spheres around particle A with radius $r_{\max }$. Usually the value of $r_{\max }$ is half of the minimum box length.

The value of $n_{\mathrm{Ca}-\mathrm{O}}$ is calculated using eqn $(10)^{19}$

$$
n_{\mathrm{Ca}}^{\mathrm{O}}\left(r_{\mathrm{s}}\right)=4 \pi \rho_{0} \int_{0}^{r_{\mathrm{s}}} g_{\mathrm{CaO}}(r) r^{2} \mathrm{~d} r
$$

For $n_{\mathrm{Ca}-\mathrm{O}}, r_{\mathrm{s}}$ is the location of the first local minimum of $g_{\mathrm{CaO}}(r)$.

Table 6 presents the effect of $\mathrm{Mg}^{2+}$ ions on the average radii of the first water shell for $\mathrm{Ca}^{2+}$ and the first water coordination number of $\mathrm{Ca}^{2+}$. The standard deviation of $R_{\mathrm{Ca}-\mathrm{O}}$ is between $0.0014 \mathrm{~nm}$ and $0.0016 \mathrm{~nm}$, and the standard deviation of $n_{\mathrm{Ca}-\mathrm{O}}$ is between 0.024 and 0.030 . The results in Table 5 show that the electrostatic field can make the radii of the first water shell of $\mathrm{Ca}^{2+}$ smaller.

According to Table 6, the addition of $\mathrm{Mg}^{2+}$ had no significant effect on $R_{\mathrm{Ca}-\mathrm{O}}$. Meanwhile, Table 5 shows that $n_{\mathrm{Ca}-\mathrm{O}}$ decreases with the increase in the number of $\mathrm{Mg}^{2+}$ ions added. The hydration between $\mathrm{Mg}^{2+}$ ions and water molecules is stronger 
than the hydration between $\mathrm{Ca}^{2+}$ and water molecules, which means the existence of $\mathrm{Mg}^{2+}$ ions can make fewer water molecule stay in the water shell of $\mathrm{Ca}^{2+}$. The addition of $\mathrm{Mg}^{2+}$ ions has no obvious effect on $R_{\mathrm{Ca}-\mathrm{O}}$, but decreases $n_{\mathrm{Ca}-\mathrm{O}}$.

The RDFs of $\mathrm{Ca}^{2+}$ and water molecules with different numbers of $\mathrm{Mg}^{2+}$ ions added under no electrostatic field (a) and under the electrostatic field (b) are presented in Fig. 6. It shows the effects of $\mathrm{Mg}^{2+}$ ions on $g_{\text {Ca-water }}(r)$. It can be seen that the first and second peaks decrease with the increase in the number of $\mathrm{Mg}^{2+}$ ions added, which means the addition of $\mathrm{Mg}^{2+}$ ions weakens the interaction between $\mathrm{Ca}^{2+}$ and water molecules. It matches the previous conclusion that $\mathrm{Mg}^{2+}$ weakens the interaction between $\mathrm{Ca}^{2+}$ and water molecules due to the $\mathrm{Mg}^{2+}$ ions binding more strongly than $\mathrm{Ca}^{2+}$ to water molecules.

According to Table 6, compared with the structure parameters under no electrostatic field, the values of $R_{\mathrm{Ca}-\mathrm{O}}$ are smaller and the values of $n_{\mathrm{Ca}-\mathrm{O}}$ are larger under the electrostatic field, which means that an electrostatic field can not only make the $\mathrm{Ca}^{2+}$ ions and water molecules gather more compactly but it can also increase the number of coordinated water molecules when no, ten or twenty $\mathrm{Mg}^{2+}$ ions are added in it. Therefore when there is an electrostatic field, the decrease of $R_{\mathrm{Ca}-\mathrm{O}}$ and the increase of $n_{\mathrm{Ca}-\mathrm{O}}$ all can be attributed to the enhanced hydration between $\mathrm{Ca}^{2+}$ ions and water molecules. The enhanced electrostatic interaction not only causes the hydrated water molecules to be closer to $\mathrm{Ca}^{2+}$ but also attracts more water molecules as coordinated water molecules. The increase of the first water coordination number of $\mathrm{Ca}^{2+}$ ions enhances their inhibition to carbonate ions, which shows that the electrostatic field decreases the formation probability of the calcium carbonate precipitate.

\section{Conclusions}

The influences of $\mathrm{Mg}^{2+}$ ions and the electrostatic field on $\mathrm{CaCl}_{2}$ aqueous solutions were studied. The effects of different numbers of $\mathrm{Mg}^{2+}$ ions were compared and the anti-fouling performance under the influence of an electrostatic field and under no electrostatic field was compared, and the structural changes and dynamic properties of $\mathrm{CaCl}_{2}$ aqueous solutions under the electrostatic field were researched by a systematic long-time, equilibrium molecular dynamics simulation. Some important conclusions were obtained.

The electrostatic field decreases the mobility of the $\mathrm{Ca}^{2+}$ ions when $\mathrm{Mg}^{2+}$ ions are added. The impurity $\mathrm{Mg}^{2+}$ ions can effectively increase the viscosity of the $\mathrm{CaCl}_{2}$ aqueous solution and decrease the self-diffusion coefficient of particles by the electrostatic interaction between $\mathrm{Mg}^{2+}$ ions and water molecules. The more $\mathrm{Mg}^{2+}$ ions are added, the bigger the viscosity of the $\mathrm{CaCl}_{2}$ aqueous solution is, and the lower the diffusion coefficient of the particles is. Therefore, the presence of $\mathrm{Mg}^{2+}$ ions can decrease the rate of the chemical reaction between $\mathrm{Ca}^{2+}$ and $\mathrm{CO}_{3}{ }^{2-}$ ions by decreasing the activity of ions.

The addition of $\mathrm{Mg}^{2+}$ ions can make the average hydrogen bond angle smaller and increase the average lifetime of hydrogen bonds. The addition of $\mathrm{Mg}^{2+}$ ions can also increase the mean dynamical residence time of water around $\mathrm{Ca}^{2+}$ ions.
The more $\mathrm{Mg}^{2+}$ ions are added, the bigger the average lifetime of hydrogen bonds is, and the bigger the mean dynamical residence time of water around $\mathrm{Ca}^{2+}$ ions is. The electrostatic field enhances the hydrogen bonding between water molecules which reflects in the decrease of the average hydrogen bond angles, the increase in the number of hydrogen bonds, and the average lifetime of hydrogen bonds.

Electrostatic fields can decrease the radii of the first water shell of hydrated $\mathrm{Ca}^{2+}$ ions. Under the action of an electrostatic field, regardless of whether or not $\mathrm{Mg}^{2+}$ ions exist, the ratio of free water molecules in the calcium chloride solution decreased and the binding force of the hydrated calcium ions to the surrounding water molecule is enhanced.

\section{Conflicts of interest}

There are no conflicts of interest to declare.

\section{Acknowledgements}

This work was financially supported by the National Natural Science Foundation of China (Grant No. 51408525 and 51608468).

\section{References}

1 J. Q. Qi, R. Guo and Y. Wang, Nanoscale Res. Lett., 2016, 11, 120.

2 L. I. Haihua, Z. F. Liu and Y. H. Gao, CIESC J., 2013, 64, 1736.

3 M. Kitamura, J. Colloid Interface Sci., 2001, 236, 318-327.

4 A. Gutjahr, H. Dabringhaus and R. Lacmann, J. Cryst. Growth, 1996, 158, 310-315.

5 N. H. DeLeeuw, J. Phys. Chem. B, 2002, 106, 5241-5249.

6 G. J. Zhao, J. Y. Liu and L. C. Zhou, J. Phys. Chem. B, 2007, 111, 8940-8945.

7 G. J. Zhao and K. L. Han, Acc. Chem. Res., 2012, 45, 404.

8 J. S. Chen, M. H. Yuan and J. P. Wang, J. Phys. Chem. A, 2014, 118, 8986.

9 P. L. De and M. L. Chávez, Langmuir, 2005, 21, 10874-10884.

10 Y. I. Cho and R. Liu, Int. J. Heat Mass Transfer, 1999, 42, 3037-3046.

11 X. Xiaokai, M. Chongfang and C. Yongchang, Chem. Eng. Technol., 2010, 28, 1540-1545.

12 J. Wang, X. Feng and W. Du, Mol. Phys., 2008, 106, 26852697.

13 X. K. Xing, C. F. Ma and Y. C. Chen, Chem. Eng. Technol., 2010, 28, 1540.

14 N. A. Hewish, G. W. Neilson and J. E. Enderby, Nature, 1982, 297, 138-139.

15 J. L. Fulton, Y. Chen and S. M. Heald, J. Phys. Chem. A, 2006, 125, 431.

16 G. Licheri, G. Piccaluga and G. Pinna, J. Phys. Chem., 1976, 64, 2437.

17 M. Zhang, C. Li and M. Benjamin, Environ. Sci. Technol., 2003, 37(8), 1663-1669.

18 M. Nedyalkova, S. Madurga and S. Pisov, J. Chem. Phys., 2012, $137,1$. 
19 A. A. Chialvo and J. M. Simonson, J. Chem. Phys., 2003, 119, 8052-8061.

20 R. E. IseleHolder, W. Mitchell and A. E. Ismail, J. Chem. Phys., 2012, 137, 1133.

21 W. F. V. Gunsteren, Biomolecular Simulation: the GROMOS96 Manual and User Guide, Zürich, Groningen, 1996.

22 Y. Han and Y. Zhao, Int. J. Electrochem. Sci., 2012, 7, 1000810026.

23 S. Tsuzuki, W. Shinoda and H. Saito, J. Phys. Chem. B, 2009, 113, 10641-10649.

24 P. Henritzi, A. Bormuth and F. Klameth, J. Chem. Phys., 2015, 143, 164502.

25 M. A. Fischler and R. C. Bolles, Commun. ACM, 1981, 24, 381.

26 Y. Han, L. Zhu and Y. Zhang, Chem. Res. Chin. Univ., 2016, 32, 1-6.

27 B. Guo, H. B. Han and F. Chai, Trans. Nonferrous Met. Soc. China, 2011, 21, s494-s498.

28 F. C. Lightstone, E. Schwegler and R. Q. Hood, Chem. Phys. Lett., 2001, 343, 549-555.

29 M. Rybicki and E. Hawlicka, Chem. Phys., 2012, 400, 79-85.

30 J. Dian, K. Christopher and G. Alan, J. Phys. Chem. B, 2006, 110, 18553.

31 S. Wei, C. Zhong and H. SuYi, Mol. Simul., 2005, 31, 555-559. 32 H. J. Bakker, Chem. Rev., 2008, 108, 1456.

33 Y. Zhu, L. Xiaohua and D. Hao, Mol. Simul., 2003, 29, 767772.
34 M. J. Wei, L. Zhang and L. Lu, Phys. Chem. Chem. Phys., 2012, 14, 16536-16543.

35 M. M. Naor, K. V. Nostrand and C. Dellago, Chem. Phys. Lett., 2003, 369, 159-164.

36 C. F. Schwenk, H. H. Loeffler and B. M. Rode, Chem. Phys. Lett., 2001, 349, 99-103.

37 D. Jiao, C. King and A. Grossfield, J. Phys. Chem. B, 2006, 110, 18553.

38 B. Hess, J. Chem. Phys., 2002, 116, 209-217.

39 W. J. Lee, J. G. Chang and S. P. Ju, Langmuir, 2010, 26, 1264012647.

40 Z. Pan, J. Chen and L. Gang, J. Chem. Phys., 2012, 136, 164313.

41 X. Zhang, Q. Zhang and D. X. Zhao, Acta Phys.-Chim. Sin., 2011, 27, 2547.

42 H. S. Lee and M. E. Tuckerman, J. Chem. Phys., 2006, 125, 154507.

43 K. Modig, B. G. Pfrommer and B. Halle, Phys. Rev. Lett., 2003, 90, 075502.

44 A. Karmakar, J. R. Choudhuri and V. K. Yadav, Chem. Phys., 2013, 412, 13-21.

45 A. Luzar and D. Chandler, Nature, 1996, 379, 55-57.

46 E. Guàrdia, J. Martí and L. García-Tarrés, J. Mol. Liq., 2005, 117, 63-67.

47 D. M. York, T. A. Darden and L. G. Pedersen, J. Chem. Phys., 1993, 32, 1443-1453. 